\title{
Comparison of 21 Days Versus 10 Days Bladder Catheterization after Hypospadias Repair
}

\section{Muhammad Abdullah, ${ }^{1}$ Muhammad Saleem, ${ }^{2}$ Ghulam Mujtaba Zafar, ${ }^{3}$ Farrukh Mehmood Sattar, Imran Hashim, ${ }^{5}$ Arslan Raza Wasti ${ }^{6}$}

\begin{abstract}
Objective: To compare 21 days versus 10 days bladder catheterization after hypospadias repair.

Methods: After approval from ethical committee, Randomised controlled trial performed,in which 196 male patients were enrolled in the study that was conducted at department of pediatric surgery, Children hospital, Lahore. All patients underwent Snodgrass procedure. Group-1 patients were considered for 10 days bladder catheterization for hypospadias repair and group-2 patients were catheterized for 21 days. Complications were documented on follow-up visits in group 1 at 1 week (17 days), 3 weeks (34 days), and 6 weeks (51 days) after catheter removal. In group 2 at 1 week (day 28th), 3 weeks (day 42nd), 6 weeks (day 63rd) after catheter removal.

Results: The mean age in group- 1 and group- 2 was $7.25 \pm 3.22$ years and $6.29 \pm 3.02$ years. There were significantly less cases of urethrocutaneous fistula in group 2 when compared to group 1. Urethro-cutaneous fistulas (UCF) developed in $13(13.26 \%), 11(11.22 \%)$ and $10(10.2 \%)$ cases at 1,3 , and 6 weeks post catheter removal follow up in group 1. While in group 2 UCF developed in $4(4.08 \%), 3(3.1 \%)$ and 2(2.04\%) at 1, 3, and 6 weeks follow up. There were 5(5.2\%) and 4(4.1\%) cases of post-operative wound infection in groups 1 and 2 respectively $(p$-value $=0.500)$. Wound dehiscence was seen in $1(1.02 \%)$ case in group 1 and was not seen in group $2(\mathrm{p}$ value $=0.500)$. glans dehiscence was not seen in group 1 while $1(1.02 \%)$ case seen in group 2 ( $\mathrm{p}$ value 0.500$)$.

Conclusion: We conclude that 21 days catheterization after hypospadias repair gives better outcome and fewer complications when compared to 10 days catheterization.

Keywords: Bladder catheterization; Hypospadias repair; Fistula formation.

How to cite: Abdullah M., Saleem M., Zafar M.G., Sattar M.F., Hasnain I, Wasti R.A. Comparison of 21 Days Versus 10 Days Bladder Catheterization for Hypospadias Repair. Esculapio 2021;17(02): 188-191.

DOI: https://doi.org/10.51273/esc21.2517216
\end{abstract}

\section{Introduction}

$\mathrm{H}$ ypospadias is regarded as quite common birth defect that affects $0.2-1 \%$ of male newborns. ${ }^{1}$ The etiology of hypospadias remains unknown and is considered multifactorial (environmental, endocrine, genetic exposure). ${ }^{2}$ Hypospadias is classified in various types on the base of meatus location i.e., glanular, sub coronal, coronal, distal, mid-penile, proximal, peno-

\begin{tabular}{|c|c|}
\hline $\begin{array}{l}\text { 1. Muhammad Abdullah } \\
\text { 3. Ghulam Mujtaba Zafar } \\
\text { 5. Imran Hashim } \\
\text { 1-6: Department of Genera }\end{array}$ & $\begin{array}{l}\text { 2. Muhammad Saleem } \\
\text { 4. Farrukh Mehmood Sattar } \\
\text { 6. Arslan Raza Wasti } \\
y \text {, Children Hospital, Lahore. }\end{array}$ \\
\hline \multicolumn{2}{|c|}{$\begin{array}{l}\text { 1-6: Department of General Surgery, Children Hospital, Lahore. } \\
\text { Correspondence: } \\
\text { Dr. Muhammad Abdullah, Department of General Surgery, Children } \\
\text { Hospital, Lahore. }\end{array}$} \\
\hline $\begin{array}{l}\text { Submission Date: } \\
\text { 1st Revision Date: } \\
\text { Acceptance Date: }\end{array}$ & $\begin{array}{l}04-05-2021 \\
17-05-2021 \\
27-05-2021\end{array}$ \\
\hline
\end{tabular}

scrotal, scrotal, and perineal. Hypospadias distal to mid penile shaft is called as anterior hypospadias that can usually be managed by single urethroplasty, especially Snodgrass tabularized incised plate (TIP) repair. Two-stage (BRACKA) is reserved for proximal hypospadias with severe chordee. ${ }^{3}$ The successful hypospadias repair comprises of 5 chronological steps: (1) Orthoplasty or penile straightening, (2) Urethroplasty, (3) Meatoplasty and Glanuloplasty, (4) Scrotoplasty, and (5) Coverage of the skin. There is a great controversy about urinary diversion after hypospadias repair. Three main protocols are being used regarding catheteriza-tion for hypospadias repair. First supra pubic drainage to avoid severe complications resulting from leakage of urine at the suture lining. ${ }^{4}$ Second per urethral catheter to the urinary bladder for about 10 days. ${ }^{5}$ and third some surgeons 
place the tube in the urethra almost distally to the position of bladder's external sphincter ${ }^{6}$, few authors also reported no diversion ${ }^{7}$. Bleustein et al,. 2001 has reported that desmoplastic as well as infla-mmatory response is manifested in sutured repair even at $21^{\text {st }}$ postop day. ${ }^{8}$ Daher et al,. 2015 proved that allo-wing the bladder catheter for about " 21 " days rather than "7" days will significantly decrease the probability of UCF.' In their study, the fistula rate was three times less in the group where urinary catheter was left for 21 days compared to where stent was left for 7 days (Beustein et al,. 2001).

There is dearth of data on hypospadias repair and its complications in Pakistan. Only one study has been done previously. In our department, the usual protocol is 10 days catheterization after hypospadias repair. Given the benefits of prolonged catheterization, we wanted to conduct this study in our population to get local data and results. If it proves to be effective, the modification in catheterization can be proposed and implemented in hospitals of our country and will ultimately result in less rate of fistula formation.

\section{Methods}

This Randomized controlled trial was performed at pediatric surgery department in children hospital Lahore. We used lottery method to allocate the groups, so that bias and confounding factors could be minimized. All male of 1 to 14 years with sub-coronal, distal, midpenile hypospadias without significant chordee, having normal labs were included in this study. After taking permission from ethical committee, 196 male patients fulfilling selection criteria were enrolled. Written informed consent was taken from parents/ attendants of each patient. All participants were examined physically by a surgery resident and attending physician. The study population was divided into 2 groups randomly using random number table. In group-1, patients were considered for 10 days bladder catheterization and in group2, patients had 21 days bladder catheterization for hypospadias repair. All patients underwent TIP procedure by senior consultants to avoid bias. Regarding number of patients according to site of hypospadias are given in table 4. Each patient in both group was given same postope-rative care. Complications were documented during ward stay and outpatient clinic visits after removal of catheter at 1,3, and 6 weeks. All the data was recorded on a self-structured proforma, demographic and other details was recorded. The quali- tative data such as complications at each follow-up was presented as frequency distribution. Quantitative data in the study like age, was presented in form mean \pm S.D (standard deviation). Chi-square test was applied to compare complications in both study groups. P-value $\leq 0.05$ was considered as significant.

\section{Results}

The mean age of the patients was $6.77 \pm 3.15$ years. The mean age in group- 1 and group- 2 was $7.25 \pm 3.22$ years and $6.29 \pm 3.02$ years with similar age

Table 1: Comparison of Postoperative UrethroCutaneous Fistulas in both Study Groups

\begin{tabular}{ccccc}
\hline & $\begin{array}{c}\text { Study } \\
\text { Groups }\end{array}$ & 1 Week & 3 Weeks & 6 Weeks \\
\hline $\begin{array}{c}\text { Urethro- } \\
\text { cutaneous } \\
\text { fistulas }\end{array}$ & Group 1 & $13(13.26 \%)$ & $11(11.22 \%)$ & $10(10.2 \%)$ \\
& Group 2 & $4(4.08 \%)$ & $3(3.1 \%)$ & $2(2.04 \%)$ \\
& P Value & 0.022 & 0.027 & 0.017 \\
\hline
\end{tabular}

Table 2: Comparison of Postoperative Early Complication in both Study Groups. $n=98$

\begin{tabular}{lccc}
\hline & $\begin{array}{c}\text { Group -1 } \\
\mathbf{n = 9 8}\end{array}$ & $\begin{array}{c}\text { Group-2 } \\
\mathbf{n = 9 8}\end{array}$ & $\begin{array}{c}\text { P- } \\
\text { Value }\end{array}$ \\
\hline $\begin{array}{l}\text { Postoperative wound } \\
\text { infection }\end{array}$ & $5(5.2 \%)$ & $4(4,1)$ & 0.50 \\
Wound dehiscence & $1(1.02 \%)$ & 0 & 0.50 \\
Glans Dehiscence & 0 & $1(1.02 \%)$ & 0.5 \\
\hline
\end{tabular}

Table 3: Comparing Complications According to Site of Meatus

\begin{tabular}{lcccccc}
\hline \multirow{2}{*}{\begin{tabular}{l}
$c$ \\
\multicolumn{1}{c}{ Complica- }
\end{tabular}} & \multicolumn{3}{c}{ GROUP 1 } & \multicolumn{3}{c}{ GROUP 2 } \\
\cline { 2 - 7 } & $\begin{array}{c}\text { Sub } \\
\text { coronal }\end{array}$ & Distal & $\begin{array}{c}\text { Mid } \\
\text { penile }\end{array}$ & $\begin{array}{c}\text { Sub } \\
\text { coronal }\end{array}$ & Distal & Mid \\
penile \\
UC Fistula & 0 & 5 & 5 & 0 & 0 & 2 \\
$\begin{array}{l}\text { Wound } \\
\text { Infection }\end{array}$ & 0 & 2 & 3 & 0 & 1 & 3 \\
$\begin{array}{l}\text { Wound } \\
\text { Dehiscence }\end{array}$ & 0 & 0 & 1 & 0 & 0 & 0 \\
$\begin{array}{l}\text { Glans } \\
\text { Dehiscence }\end{array}$ & 0 & 0 & 0 & 0 & 0 & 1 \\
\hline
\end{tabular}

distribution in both study groups, p-value was insignificant. Details of Urethro-cutaneous fistulas development are shown in table 1 and details of rest of Table 4: Group Distribution According to Site of Meatus

\begin{tabular}{lccc}
\hline & $\begin{array}{c}\text { SUB } \\
\text { CORONAL }\end{array}$ & DISTAL & $\begin{array}{c}\text { MID } \\
\text { PENILE }\end{array}$ \\
\hline Group 1 (10 days) & 16 & 57 & 25 \\
Group 2 (21 days) & 16 & 56 & 26 \\
\hline
\end{tabular}


early complications are given in table 2 .

\section{Discussion}

Hypospadias is reffered to an ectopically placed urethral aspect of penis or more proximal on scrotum to perineum. ${ }^{10}$ Despite the advanced surgical techniques, postoperative complications may occur. These complications typically develop within 6 months of urethroplasty. ${ }^{9}$ Various postoperative complications of any hypospadias repair may include edema, bleeding, urethral fistula, complete or partial disruption of the urethral repair, wound infection and dehiscence. ${ }^{11,12}$ The most important comp-lication is urethra-cutaneous fistula and repair disruption which may require further surgeries for re-repair that often become more difficult due to scarring of local tissue making it more prone to complications. ${ }^{13}$ Some authors advocated that catheter for 3 weeks may reduce fistula formation. In this context we carried out this study. In our study statistically difference in UCF in group $1 \& 210.2 \%$ \& $2.04 \%$ (p-value 0.017 ) comparing with Daher $17.89 \%$ \& $7.8 \%$ respectively. ${ }^{9}$ While in another study Faustin et al., 2016 fistula rate was $8 \% .{ }^{14}$ Infection rate in our study was $5.2 \%$ \& $4.1 \%$ (p-value 0.500 ) While in Faustin study infection rate was $8 \%{ }^{14}$ Wound dehiscence in our study was $1.02 \%$ \& $0 \%$ (p-value 0.500 ) in group 1 and 2 respectively, while in Faustin Partial or total breakdown of repair was $8 \%$ in patient with 3 weeks catheterization. ${ }^{14}$ Glans dehiscence in our study was $0 \%$ \& $1.02 \%$ (p-value 0.500 ) While in Faustin study Breakdown repair was $8 \%$. In Daher study no postoperative wound infection, glans dehiscence or complete wound dehiscence was observed. A study by Daher et al., 2015 investigated role of duration of catheterization in hypospadias repair and found good results in terms of lesser postoperative complications especially urethral fistula in case of prolonged catheterization. The limitations of their study include its design, selection of patients, and duration of catheterization. I believe that each of these factors is an individual factor for development of complications and lack of randomization can create potential bias in the study.

Our study is randomized controlled trial and I have specified type of hypospadias to remove selection bias. Moreover we have used 10 days instead of seven days as I believe 7 days are too early for removal of catheter that theoretically increases risk of fistula formation.
In study of Daher P et al., 2015, they found fistula rate of $22.4 \%$ in patients where catheter was kept for 1 week whereas fistula rate of $7.4 \%$ in case of 3 weeks catheterization. The difference in fistula rate in their study was statistically significant. Our study endorses the results of Daher's study and our results can be considered more valuable on account of better planned study and good selection criteria and less chance of selection bias. In the index study, $10.2 \%$ cases got fistula with 10 days catheterization, and $2.04 \%$ of patients develop fistula with 21 days of catheterization (at 6 weeks after catheter removal). Arda et al., 2001 compared use of stent and catheter. The results showed that all stented patients strained at first voiding. Some patients showed pain, and only few showed voiding with in the first 8 hours. The catheterized group did not show any such problems. The findings also show that bladder catheterization can avoid these complications. ${ }^{15}$ We study also showed better results with prolonged catheterization. The speculated benefits with prolonged catheterization could be complete absence of urinary leak in the peri-neourethral space due to prevention of direct voiding thus leading to prolonged time for proper healing of neo-urethra. Moreover, meatal stenosis is also prevented through the prolonged catheterization. Opponents of catheterization give opinion that it acts as foreign body and can detriment results.

Although no statistically significant difference was observed for secondary outcomes like wound infection, wound dehiscence (complete urethral dehiscence) or isolated glans dehiscence in both groups, the statistically difference in UCF in both groups favor prolonged catheterization. Prolonged catheterization may prevent meatal stenosis although this parameter was not studied in our series. Daher P et al., 2015 found less meatal stenosis cases in prolonged catheterization group although it was not statistically significant.

Bluestein et al., 2001 found that even by day-21 postoperatively, the sutured repair still presented with a desmoplastic and inflammatory response. This further supports our belief to leave the catheter till the $21 \mathrm{st}$ postoperative day.

Overall rate of complications was reported as $22.1 \%$ $(n=21)$ for group 1 (1 week) while for group 2 (for 3 weeks) it was reported as 7.4\% $(n=7),[p=.005]$ (Daher $\mathrm{P}$ et al., 2015). The cases in group 1 presented with coronal fistulas more commonly as compare to the cases in group 2 ("13.7\%" versus $3.2 \%)[\mathrm{P}=.01]$. We 
in this study also found favorable results in group-2 when compared to group-1.

\section{Conclusions}

Through the findings of this study we conclude that 21 days catheterization for hypospadias repair gives better outcome and fewer complications when compared to 10 days catheterization. So paediatric surgeons should be encouraged to leave the catheter for 21 days instead of 10 days.

\section{Conflict of Interest: None}

\section{References}

1. Toppari J, Virtanen HE, Main KM, Skakkebaek NE. Cryptorchidism and hypospadias as a sign of testicular dysgenesis syndrome(TDS): environmental connection. Birth Defects Research Part A: Clinical and Molecular Teratology. 2010 Oct;88(10):910-9.

2. Kraft P, Vaché KB, Frede HG, Breuer L. CMF: a hydrological programming language extension for integrated catchment models. Environmental Modelling \& Software. 2011 Jun 1;26(6):828-30.

3. Castagnetti M, El-Ghoneimi A. The influence of perioperative factors on primary severe hypospadias repair. Nature Reviews Urology. 2011 Apr;8(4):198.

4. Roushdy R, Sieverding M, Radwan H. The impact of water supply and sanitation on child health: Evidence from Egypt.

5. Arda IS, Mahmutoğlu M. Urethral catheterization in hypospadias surgery: Should the device enter the bladder or be made a urethral stent?. Journal of pediatric surgery. 2001 Dec 1;36(12):1829-31.

6. Ahmed N, Ahmed I, Faraz O, Safdar CA, Saleem M, Awan SH, Yusuf J. Comparison between urethroplasty with and without stent for hypospadias in terms of postoperative urethrocutaneous fistula formation. Pakistan Armed Forces Medical Journal. 2018 Dec 31;68(6): 1511-6.

7. El-Sherbiny DA, Khalifa AE, Attia AS, Eldenshary EE. Hypericum perforatum extract demonstrates antioxidant properties against elevated rat brain oxidative status induced by amnestic dose of scopolamine. Pharmacology Biochemistry and Behavior. 2003 Dec 1; 76(3-4):525-33.

8. BLEUSTEIN CB, ESPOSITO MP, SOSLOW RA, FELSEN D, POPPAS DP. Mechanism of healing following the Snodgrass repair. The Journal of urology. 2001 Jan;165(1):277-9.

9. Daher P, Khoury A, Riachy E, Atallah B. Three-week or one-week bladder catheterization for hypospadias repair? A retrospective-prospective observational study of 189 patients. Journal of pediatric surgery. 2015 Jun 1;50(6):1063-6.

10. Leung AK, Robson WL. Hypospadias: an update. Asian journal of andrology. $2007 \mathrm{Jan} ; 9(1): 16-22$.

11. Stokowski LA. Hypospadias in the neonate. Advances in Neonatal care. 2004 Aug 1;4(4):206-15.

12. Snyder CL, Evangelidis A, Hansen G, Peter SD, Ostlie DJ, Gatti JM, Gittes GK, Sharp RJ, Murphy JP. Management of complications after hypospadias repair. Urology. 2005 Apr 1;65(4):782-5.

13. Cheng EY, Vemulapalli SN, Kropp BP, Pope JC, Furness PD, Kaplan WE, Smith DP. Snodgrass hypospadias repair with vascularized dartos flap: the perfect repair for virgin cases of hypospadias?. The Journal of urology. 2002 Oct;168(4 Part 2):1723-6.

14. Felicien MT, Makon AN, Kamadjou C, Fossi G, Le Coultre C, Andze OG, Sosso MA, Mure PY. Our experience of proximal hypospadias repair using the Cloutier-Bracka technique at the Gynaeco-Obstetric and Paediatric Hospital, Yaounde-Cameroon. African journal of paediatric surgery: AJPS. 2016 Oct; 13(4):193.

15. Arda IS, Mahmutoğlu M. Urethral catheterization in hypospadias surgery: Should the device enter the bladder or be made a urethral stent?. Journal of pediatric surgery. 2001 Dec 1;36(12):1829-31.

\section{Authors Contribution}

M.A: Conceptualization of Project

M.S, F.M: Data Collection

G.M.Z, I.H: Literature Search

A.R: Data Analyze 